\title{
$\left[{ }^{18}\right.$ F]Fluorination/Decarbonylation: New Route to Aryl $\left[{ }^{18} \mathrm{~F}\right]$ Fluorides
}

\author{
PULAK K. CHAKRABORTY and MICHAEL R. KILBOURN*
}

Division of Nuclear Medicine, Department of Internal Medicine, University of Michigan, Ann Arbor, MI 48109, U S.A

(Received 10 April 1991)

\begin{abstract}
A new route to aryl $\left[{ }^{18} \mathrm{~F}\right]$ fluorides without electron withdrawing ring substituents has been developed. $\left[{ }^{18} \mathrm{~F}\right]$ Fluorobenzaldehydes, prepared from no-carrier-added (NCA) $\left[{ }^{18} \mathrm{~F}\right]$ fluoride using nucleophilic aromatic substitution of fluoro or nitro groups, were decarbonylated using palladium on charcoal (Pd-C). By this approach 2-methoxy-4-nitrobenzaldehyde was converted to NCA 3-[ $\left.{ }^{18} \mathrm{~F}\right]$ fluorophenol $(25-30 \%$, EOB) and 4-fluoro-2-methoxy-5-methylbenzaldehyde to carrier-added (CA) 3-[ ${ }^{18}$ F]fluoro-4-methylphenol (30-40\%. EOB). Overall synthesis time was about $2 \mathrm{~h}$. Since the 4-fluoro-2-methoxy-5-methylbenzaldehyde was in turn prepared by methylation and regiospecific formylation of 3-fluoro-4-methylphenol, the overall process represents use of a removable activating group for nucleophilic aromatic substitution with $\left[{ }^{18} \mathrm{~F}\right]$ fluoride for preparation of $\mathrm{CA}$ and $\mathrm{NCA}$ aryl $\left[{ }^{18} \mathrm{~F}\right]$ fluorides.
\end{abstract}

\section{Introduction}

The Balz-Schiemann reaction, the triazene decomposition reaction and electrophilic fluorination are commonly used methods for the syntheses of aryl $\left[{ }^{18} \mathrm{~F}\right]$ fluorides which are not activated by an electron withdrawing group. The radiochemical yields of these reactions are often very low and more importantly, as in the case of Balz-Schiemann and electrophlic fluorination, the reactions provide products of low specific activity. Modifications of these reactions have been investigated ( $\mathrm{Ng}$ et al., 1981; Guddat et al., 1989; Satyamurthy et al., 1990) to overcome the difficulties associated with low yields and low specific activities. In addition, two other new approaches $(\mathrm{Ng}$ et al., 1981; Ehrenkaufer et al., 1982) have also been investigated as methods potentially suitable for incorporating $\mathrm{NCA}\left[{ }^{1 k} \mathrm{~F}\right]$ fluornde into an unactivated aromatic nucleus. $p$-Fluoro- $n$-anisidine was prepared ( $\mathrm{Ng}$ et al., 1981) by decomposition of $m$-methoxy aryl azides in anhydrous hydrogen fluoride, and then deaminated to yield $o$-fluoroanısole in good yield. However, this reaction fails with oxygen substituents ortho to the azide, and with larger $O$-alkyl groups. Attempted syntheses (Ehrenkaufer et al., 1982) of aryl $\left[{ }^{18} \mathrm{~F}\right]$ fluorides by catalytic decarbonylation of aroyl $\left[{ }^{18} \mathrm{~F}\right]$ fluorides with Wilkinson's catalyst $\left[\left(\mathrm{Ph}_{3} \mathrm{P}\right)_{3} \mathrm{RhCl}\right]$ were unsuccessful, leading instead to decarbonylation products (benzene).

*Author for correspondence at. Michael R. Kilbourn, Cyclotron/PET Facility, 3480 Kresge III, University of Michigan, Ann Arbor, MI 48109, U.S.A.
An electron withdrawing group on an aromatıc ring provides activation for nuclcophilic aromatic displacement reactions using $\left[{ }^{18} \mathrm{~F}\right]$ fluoride ion, and is the method of choice for preparing aryl $\left[{ }^{18} \mathrm{~F}\right]$ fluorides in high yield and high specific activity. However, for the application of nucleophilic aromatic substitution to the synthesis of an aryl $\left[{ }^{18} \mathrm{~F}\right]$ fluoride without an electron withdrawing group, it would be essential to remove or manipulate such an activating group in some later stage of the synthesis. Shiue et al. (1984) reported the synthesis of $\mathrm{NCA}\left[{ }^{18} \mathrm{~F}\right]$ fluorobenzene from $p$-chloro-nitrobenzene in good yield through displacement of chloride by $\left[{ }^{18} \mathrm{~F}\right]$ fluoride and subsequent removal of the nitro group by reduction/ diazotization. This method has not been attempted on more complex molecules. Recently Hwang et al. (1991) reported a new procedure for syntheses of 4-[ $\left[{ }^{18} \mathrm{~F}\right]$ fluoro-1-alkyl-benzenes which involved ${ }^{18} \mathrm{~F}$ for- $\mathrm{NO}_{2}$ substitution of 4-nitroacetophenone or 4nitrophenylcyclopropyl ketone and the subsequent reductions (triethyl silane/trifluoroacetic acid) of the intermediate ${ }^{18} \mathrm{~F}$-labeled ketones.

Aldehydes are often used as activating groups in nucleophilic aromatic displacement reactions by $\left[{ }^{18}\right.$ F]fluoride (Kilbourn, 1990). We have recently reported that the methoxy substituted $\left[{ }^{18} \mathrm{~F}\right]$ fluorobenzaldehydes can be converted to $\left[{ }^{18} \mathrm{~F}\right]$ fluorophenols and $\left[{ }^{18} \mathrm{~F}\right]$ fluorocatechols by Baeyer-Villiger oxidation reactions (Chakraborty and Kilbourn, 1991). In an extension of that work, we became interested in the feasibility of decarbonylation of such $\left[{ }^{18} \mathrm{~F}\right]$ fluorobenzaldehydes to the corresponding aryl $\left[{ }^{18} \mathrm{~F}\right]$ - 
fuorldes which would then lack the electron withdrawing substitutent. Decarbonylation of a number of substituted aryl aldehydes in the presence of palladium on charcoal at elevated temperature has been previously reported (Hawthorne and Wilt. 1960). Since this method has not been applsed to the syntheses of aryl $\left[{ }^{18} \mathrm{~F}\right]$ fluorides, we report here the decarbonylation reaction applied to two representative $\left[{ }^{18} \mathrm{~F}\right]$ fluorobenzaldehydes, $4-\left[{ }^{18} \mathrm{~F}\right]$ fluoro-2methoxy-5-methylbenzaldehyde $\left(\left[{ }^{18} \mathrm{~F}\right] 3\right)$ and $4-\left[{ }^{18} \mathrm{~F}\right]$ fluoro-2-methoxybenzaldehyde $\left(\left[{ }^{1 x} \mathrm{~F}\right] 5\right)$.

\section{Experimental}

Materials and methods

All reagents, $10 \% \mathrm{Pd}-\mathrm{C}$ and anhydrous solvents were purchased for Aldrich Chemical Company The preparations of 2-methoxy-4-nitrobenzaldehyde (4) and 4-fluoro-2-methoxybenzaldehyde (5) have been reported earlier (Chakraborty and Kilbourn, 1991). Nylon membrane filters (Nylon Acrodisc 13,0 $2 \mu \mathrm{m}$ ) were obtained from Gelman Scrences, Ann Arbor, Mich. Analytical thın layer chromotography (TLC) was performed using an Analtech precoated silica gel (GHLF) glass platc Mcrek silica gel (silicagel 60 . $70-230$ mesh) was used for column chromatography. NMR spectra were obtaned on Bruker $360 \mathrm{MH}$, spectrometer using $\mathrm{CDCl}_{3}$ as the solvent and tetramethyslane as the internal standard. Infrared spectra were taken on a Perkin Elmer 1420 spectrometer. Low resolution mass spectra were run on a Finnigan 4021 quadrupole mass spectrometer either in electron impact $(70 \mathrm{eV})$ or in chemical 1onization (CI) mode High resolution (exact mass) mass measurements were done on VG 70-250-S instrument with perfluorokerosene as reference compound Meling points are reported uncorrected. Radiochemical yields reported here are decay corrected.

3-Fluoro-4-methylphenol (I) This was prepared from 3-fluoro-4-methylaniline following the known procedure (Ungnade and Orwoll. 1955) in $90 \%$ yield, mass spec. mie (rel. int.) $126\left(\mathrm{M}^{+} .80\right), 125$ (100). 108 (5). 97 (7), 95 (6), 77 (8). Benzoyl derrivative. m.p 75-76 C (lit. m.p 77 C; Brown et al . 1949)

3-Fluoro-4-methylamisole (2) Methylation $\left[\left(\mathrm{CH}_{3}\right)_{2} \mathrm{SO}_{4}: \mathrm{K}_{2} \mathrm{CO}_{3}\right]$ of 1 gave the desired compound in $63 \%$ yield after purification by column chromatography

4-Fluoro-2-methoxy-5-methylbenzaldehyde (3). 3Fluoro-4-methylanısole was formylated using $\alpha, x-$ dichloromethyl methyl ether in presence of titanium(IV) chloride following the procedure of Gross el al. (1963) to give 3 in $73 \%$ yleld after purification by column chromatography. $\mathrm{m} \mathrm{p}$ 64-65- C: $R_{\mathrm{f}}(15: 85$ EtOAc: Hex $)=0.48$; mass spec. (rel int.) $168\left(\mathrm{M}^{+}, 100\right), 167(59), 151(32), 137$ (14). 123 (18), 122 (17), 109 (30); 'H-NMR: $\delta 2.21$ (3H, s, $\left.\mathrm{OCH}_{3}\right), \quad 3.89\left(3 \mathrm{H}, \quad\right.$ s. $\left.\mathrm{Ar}-\mathrm{CH}_{3}\right), 6.64(1 \mathrm{H}, \quad$ d. $\mathrm{J}_{H F}^{\text {wrtho }}=11.3 \mathrm{~Hz} . \mathrm{ArH}-3$ ), 767 (1H. d. $J_{\mathrm{Hr}}^{\text {metu }}=9 \mathrm{~Hz}$, ArH-6), 10.33 (1H. S, - CHO): IR (KBr) 1660
(CHO), 1610, $1570 \mathrm{~cm}$ !. Anal. (exact mass): calcd for $\mathrm{C}_{4} \mathrm{H}_{4} \mathrm{FO}_{2}$ 168.0587, found, 168.0595

Sinthesis of 3-fluorophenol from 4-fluoro-3methoxybenzaldehyds (5) bv decarbonvlation and demethylation. A mixture of $10 \% \mathrm{Pd}-(\mathrm{C}(75 \mathrm{mg})$ and 4-fluoro-2-methoxybenzaldehyde (77 $\mathrm{mg})$ in $3 \mathrm{~mL}$, of 1.2.3.4-tetramethylbenzene was heated at 235 240 ( for $4 \mathrm{~h}$ The reaction mixture was then cooled. filtered over celite and washed with pentane The filtrate was concentrated under reduced pressure and dissolved in $15 \mathrm{~mL}$ of dry $\mathrm{CH}_{2} \mathrm{Cl}_{2}$. The solution was cooled to $-70 \mathrm{C}$ and a solution of boron tribromide (1 $\mathrm{M}$ in $\mathrm{CH}_{2} \mathrm{Cl}_{2}, 4 \mathrm{~mL}$ ) was added dropwise After surming for another $30 \mathrm{~min}$ cold bath was removed and surring contınued for another $2.5 \mathrm{~h}$. Then excess $\mathbf{B B r}$; Wat decomposed by addition of lee and product was extracted into $2 \mathrm{~N} \mathrm{NaOH}$. The aqueous layet was acidified with cold $6 \mathrm{~N} \mathrm{HCl}$ solution and extracted with ethylacetate Ethylacetate was washed with water, dried and evaporated under reduced pressure to give a product in $75 \%$ yicld TLC and mass fragmentation pattern were identical with those at authentic 3-fluorophenol. Anal (exact mass) calcd for $\mathrm{C}_{h} \mathrm{H}_{5} \mathrm{OF}$ 112.0324, found, 1120313

Sinthess of 3-Huoro-4-methiphenol ( 1 ) bi decat honvlation and demethilatom of 4-fluore-2-methon:5-methylhenzaldehide (3) 4-Fluoro-2-methoxy-5methylbenzaldehyde $(84 \mathrm{mg})$ was decarbonylated with $10^{\circ} \% \mathrm{Pd}-\mathrm{C}(75 \mathrm{mg})$ in $3 \mathrm{~mL}$ of $1.2,3,4$-tetramethylbenzene at $240250 \mathrm{C}$ for $5 \mathrm{~h}$ The muture was filtered over celite, washed with pentane and filtrate was concentrated. Demethylation with $\mathrm{BBr}_{3}$ and work up as above provided a produce $\left(855_{0}\right)$ identical (TLC and mass spec) with a sample of 1 prepared from 3-fluoro-4-methylaniline (eale intra) Anal (exact mass) calcd for $\mathrm{C}_{-} \mathrm{H}_{7} \mathrm{OF} 126.04 \times 1$. found, 1260478

Preparation of potasium I"FJfluonde Kiptofic $222\left[{ }^{14} \mathrm{~F}\right]$ Fluoride $10 n$ was produced by proton irradiation of ${ }^{\prime} \mathrm{O}$ enriched water $\left(97^{\circ} \%\right.$. Isotec) held in all-silver target $(1 \mathrm{~mL}$ target volume. Mulholland it al. 1989) An ahquot of the $\left[{ }^{18}(0]\right.$ water ${ }^{1 \times}$ Fjthoride solution was added to a mixture of the ammopolyether $4,7,13,16,21,24$-hexaoxa-1,10-dia $/$ ahicyclo[8.8.8]hexacosane (Kryptofix 222) (10 mg. () $027 \mathrm{mmol}$ ) and potassium carbonate $11 \mathrm{mg}$, $0007 \mathrm{mmol}$ ) and dried under a stream of nutrogen at $100 \mathrm{C}$ in a glass sample val (Hamacher 't al 1986) Residual water was removed by azeotropic distillation with acetonitrile, and the residue dissolved in DMSO for use in fluorination reactions

General procedure for $\left[{ }^{1 x} F\right]$ fluorde $u$ in displacement reactons. Resolubilized $\mathrm{K}^{1 \times} \mathrm{F}$ Kryplofix (15-25 mC1) in $200 \mu \mathrm{L}$ of anhydrous DMSO was added $103+\mathrm{mg}$ of substrate 3,4 or 5 , and heated at 120 C for $10 \mathrm{~mm}$ The solution was then cooled, diluted with wate and passed through C-18 Sep-Pak After washing C -18 Sep-Pak with another $5 \mathrm{~mL}$ of water. product was eluted with ether, dried $\left(\mathrm{Na}_{2} \mathrm{SO}_{4}\right)$ and after filtration. solvent was evaporated in a stream of $N_{\text {. }}$ The 
radiochemical yields were $60-70 \%$. These ${ }^{18} \mathrm{~F}$-labeled products were used for the next step without further purification.

Procedures for decarbonylation of $\left[{ }^{18} F\right]$ fluorobenzaldehydes. (A) The decarbonylation of $\left[{ }^{18} \mathrm{~F}\right]$ fluorobenzaldehydes $\left[{ }^{18} \mathrm{~F}\right] 3$ and $\left[{ }^{18} \mathrm{~F}\right] 5(5-10 \mathrm{mCi})$ was done by heating the compounds at $250-255^{\circ} \mathrm{C}$ in 150-200 $\mu \mathrm{L} \mathrm{12,3,4-tetramethylbenzene} \mathrm{in} \mathrm{presence} \mathrm{of}$ $10 \% \mathrm{Pd}-\mathrm{C}(30-40 \mathrm{mg})$ for $50-60 \mathrm{~min}$. The solution was then cooled and filtered (celite or nylon membrane). The radiochemical yields of the products after filtration of catalyst were $70-80 \%$ with radiochemical puritıes $>90 \%$ and were used for the demethylation step without 1 solation of the products. (B) The decarbonylation of compound $\left[{ }^{18} \mathrm{~F}\right] 3$ was also done in 2,4,6-trimethylpyridine under the same conditions as above. The crude mixture was filtered through a membrane filter, acidified with cold $6 \mathrm{~N} \mathrm{HCl}$ solution and $\left[{ }^{18} \mathrm{~F}\right] 2$ was isolated by extraction into pentane. The radiochemical yields of the products were $60-70 \%$ with radiochemical purities $>90 \%$.

Procedure for methyl ether cleavage of $\left[{ }^{18} F\right]$ fluoroanisoles. Cleavage of methyl ethers was done by adding a solution of $\mathrm{BBr}_{3}$ (excess) in methylene chloride to a cold $(0-5 \mathrm{C})$ solution of $\left[{ }^{18} \mathrm{~F}\right]$ fluoroanisole $\left[{ }^{18} \mathrm{~F}\right] 2$ or $6(1-4 \mathrm{mCi})$ in 1,2,3,4-tetramethylbenzene. After keeping the reaction mixture at room temperature for 15-20 min, excess $\mathrm{BBr}_{3}$ was decomposed by addition of ice and $\left[{ }^{18} \mathrm{~F}\right]$ fluorophenols were extracted into sodium hydroxide solution. Aqueous portion was then acidified with cold dilute sulfuric acid, and product isolated using a C-18 Sep-Pak. The radiochemical yields of $\left[{ }^{18} \mathrm{~F}\right]$ fluorophenols were $60-70 \%$ and radiochemical purities $>95 \%$.

\section{Results and Discussion}

The $\left[{ }^{18} \mathrm{~F}\right]$ fluorination'decarbonylation approach to $\left[{ }^{18}\right.$ F]fluoroanisoles is shown in Fig. 1. and represents a new concept for the preparation of aryl $\left[{ }^{18} \mathrm{~F}\right]$ fluorides bearing no electron withdrawing group. The application of this procedure involves three steps: (1) syntheses of appropriately substituted benzaldehyde precursors, (2) nucleophilic aromatic displacements by $\left[{ }^{18} \mathrm{~F}\right]$ fluoride and (3) decarbonylations of the intermediate $\left[{ }^{18} \mathrm{~F}\right]$ fluorobenzaldehydes.

\section{Sytheses of substituted benzaldehyde precursors}

Syntheses of 2-methoxy-4-nitrobenzaldehyde (4) and 4-fluoro-2-methoxybenzaldehyde (5) have been reported earlier (Chakraborty and Kilbourn, 1991).

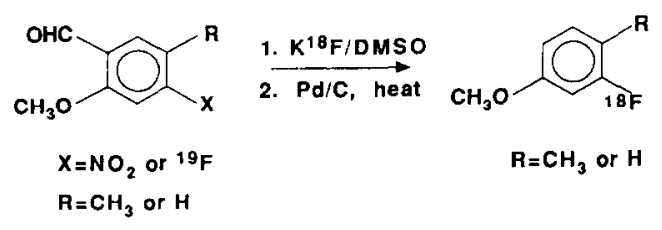

Fig. 1. General approach to aryl $\left[{ }^{18}\right.$ F fluorides via decarbonylation reactions.

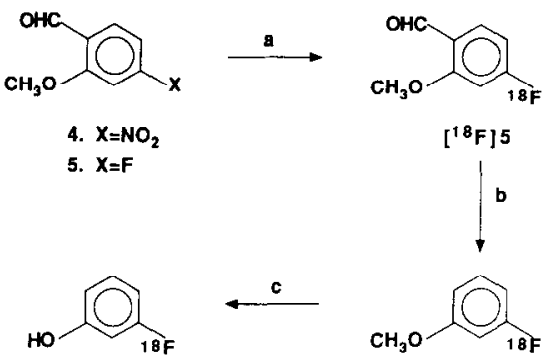

a, K18F/Kryptofix/DMSO; b, 10\% Pd.C, solvent, heat; c, $\mathbf{B B r}_{3}$

Fig. 2. Synthesis of CA 3-[ $\left[{ }^{18}\right.$ F]fluoro-4-methylphenol from 3-fluoro-4-methylphenol

4-Fluoro-2-methoxy-5-methylbenzaldehyde (3) was prepared (Fig. 2) in $73 \%$ yield by formylation of 3-fluoro-4-methylanisole using $\alpha, \alpha$-dichloromethyl methyl ether in presence of titanium(IV) chloride following the literature procedure (Gross et al., 1963). In the ${ }^{1} \mathrm{H}-\mathrm{NMR}$ spectrum of the compound, two doublets observed at $\delta 6.64(\mathrm{~J}=11.3 \mathrm{~Hz})$ and 7.67 $(\mathrm{J}-9.0 \mathrm{~Hz}$ ), each integrating for one proton, could be assigned to protons ortho (H-3) and meta (H-6) with respect to the fluorine, based on the chemical shifts and ${ }^{19} \mathrm{~F}-{ }^{-1} \mathrm{H}$ coupling constants, supporting the position of aldehyde as para to fluorine. However, the position (ortho or para) of the aldehyde with respect to a leaving group in the aromatic ring is irrelevant since either compound would provide the same product $\left[{ }^{18} \mathrm{~F}\right] 2$ after $\left[{ }^{18} \mathrm{~F}\right]$ fluorination and decarbonylation reactions.

\section{Nucleophilic aromatic displacement reaction by $\left[{ }^{18}\right.$ F]fluoride ion}

Nucleophilic aromatic displacement reactions using $\mathrm{K}^{18} \mathrm{~F} / \mathrm{Kryptofix}$ in DMSO at $120^{\circ} \mathrm{C}$ with all the substituted benzaldehydes gave corresponding $\left[{ }^{18} \mathrm{~F}\right]$ fluorobenzaldehydes in $60-70 \%$ yields with $>90 \%$ radiochemical purities. However, we have not removed the chemical impurities which arise from use of the nitrobenzaldehyde and the $\left[{ }^{18} \mathrm{~F}\right]$ fluorobenzaldehyde was used without purification for the next step.

\section{The decarbonylation of $\left[{ }^{18} F\right]$ fluorobenzaldehydes}

The decarbonylation of substituted $\left[{ }^{18} F\right]$ fluorobenzaldehydes is based on the work of Hawthorne et al. (1960). Reactions were done by heating the $\left[{ }^{18} \mathrm{~F}\right]$ fluorobenzaldehydes in 1,2,3,4-tetramethylbenzene in the presence of $10 \%$ palladium on charcoal. The Pd-C could be removed by filtration on celite or a nylon membrane (pore size $0.2 \mu \mathrm{m}$ ) filter. The latter procedure was found to be very convenient and the volume of the solution could be kept to a minimum after filtration and rinsing with solvent. The radiochemical yields of decarbonylation reactions after filtration of $\mathrm{Pd}-\mathrm{C}$ were $70-80 \%$ and radiochemical purities as indicated by TLC were $>90 \%$. The decarbonylation products, obtained as solutions in $1,2,3,4$. 


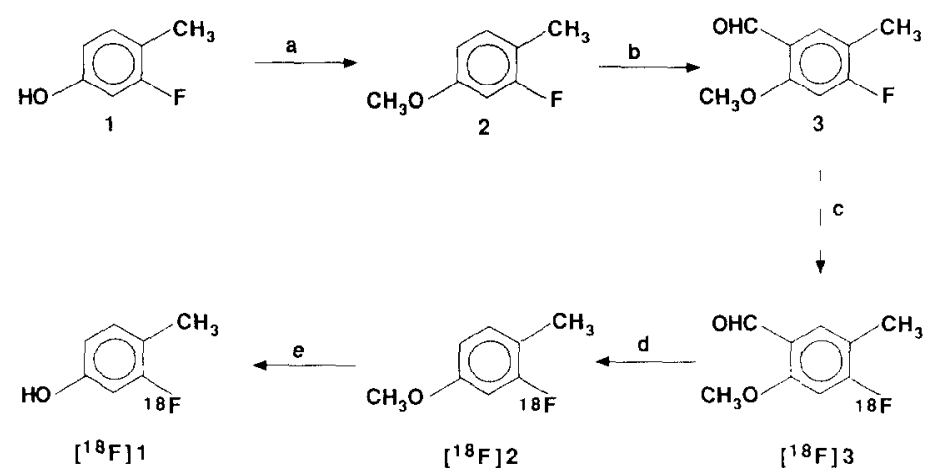

a, $\left(\mathrm{CH}_{3}\right)_{2} \mathrm{SO}_{4} / \mathrm{K}_{2} \mathrm{CO}_{3} ; \mathrm{b}, \mathrm{Cl}_{2} \mathrm{CHOCH}_{3} / \mathrm{TiCl}_{4} ; \mathrm{c}, \mathrm{K}^{18 \mathrm{~F}} / \mathrm{Kryptofix} / \mathrm{DMSO}$;

$d, 10 \% \mathrm{Pd}-\mathrm{C}$, solvent, heat; $\mathrm{e}, \mathrm{BBr}_{3}$

Fig 3 Syntheses of CA and NCA $3-\left.\right|^{18}$ F fluorophenols

tetramethylbenzene, were used directly in the demethylation reactions using $\mathrm{BBr}_{3}$. The final produets, $\left[{ }^{18} \mathrm{~F}\right]$ fluorophenols, were extracted into $\mathrm{NaOH}$ solution, acidified with dilute sulfuric acid and isolated by $\mathrm{C}-18 \mathrm{Sep}-\mathrm{Pak}$. The radiochemical puritıes of $\left[{ }^{18} \mathrm{~F}\right]$ fluorophenols as determined by TLC were $>95 \%$. This acid/base extraction also provided separation of products $\left[{ }^{18} \mathrm{~F}\right] 1$ and 7 from the solvent (1.2,3,4-tetramethylbenzene). However, the intermediate decarbonylation products such as $\left[{ }^{18} \mathrm{~F}\right]$ fluoroanisole $\left[{ }^{38} \mathrm{~F}\right] 2$ could be more easily isolated by substıtutıng 2,4,6-trımethylpyridine for 1,2,3,4-tetramethylbenzene; upon acid workup of the reaction, the product could be extracted into pentane, with the basic solvent retained in the acidic aqueous layer Use of substituted pyridine as a solvent would be of particular value for the preparation of non-phenolic aryl $\left[{ }^{18} \mathrm{~F}\right]$ fluorides

The time, temperature and quantity of Pd-C necessary for these decarbonylation reactions were not fully optımized and might vary depending on the substrate (Hawthorne and Wilt, 1960). At the temperatures we have used here, the TLC analyses showed the decarbonylated products were major $(>90 \%)$ components in all cases after 50 min reaction time. Shorter reaction times gave varıus percentages of starting material and decarbonylated product. Although the decarbonylation was done for $50-60 \mathrm{~mm}$, the overall procedures of $\left[{ }^{18} \mathrm{~F}\right]$ fluormation and decarbonylation could be conveniently performed within $2 \mathrm{~h}$. Further elaboration of the product aryl $\left[{ }^{18} \mathrm{~F}\right]$ fluorides to more complex structures would require additional steps and synthesis time.

The identity of all the aryl $\left[{ }^{18} \mathrm{~F}\right]$ lluorides were determined by TLC comparisons with that of the unlabeled authentic compounds prepared by independent methods. In addition, the same procedures of decarbonylation and demethylation were performed on the corresponding "cold" unlabeled fluorobenzaldehydes 3 and $\mathbf{5}$. The isolated fluorophenols were identified by comparisons (TLC, mass spec fragmentation pattern and high resolution mass spectra) with authentic samples. Throughout this study, we have determined the identity and purity of radiolabeled products only, and have not accounted for chemical impurities such as the 3-nitroanisole which would be formed by decarbonylation of the 2-methoxy-4-nitrobenzaldehyde used as one of the precursors (Hawthorne and Wilt, 1960) Formation of such impurities could be avolded by the application of aryltrmethylamonum triflates as precursors for $\left[{ }^{18} \mathrm{~F}\right]$ fluorination (Haka et al.. 1989)

The mechanism of the decarbonylation reaction is not well understood (Wilt and Abegg, 1968). and there have been limited studies on the scope and the limitations of this reaction (Hawthorne and Wilt. 1960: Newman and Zahm, 1943, Rylander, 1973) Carbomethoxy, lactone, methoxy, methylenedioxy, 1sopropylidenedioxy, nitro, carboxylic acid and substituted amino substituents on aromatic rings are reported to be unaffected by the reaction conditions (Basa, 1975; Carabateas et al. 1984; Ish1 et al, 1990, Rylander, 1973; Shirasaka et al, 1990: Tadano et al. 1987). The decarbonylation can also be successfully applied to pyridinecarboxaldehydes (Bailey 't al. 1973; Hawthorne and Wilt, 1960; Kurby et al . 1979) Certain functional groups, among them aliphatic and olefinic aldehydes, ketones and carbon-oxygen single bonds adjacent to aromatic nucleus, aliphatic carboxylic acids, aryl chlorides, anhydrides, unsaturated esters, aryl formates. primary alcohols and acyl halides, may be etther reduced or decarbonylated by Pd-C (House, 1972: Isabelle et al 1977. Rylander. 1973. Shishido et al.. 1987 Verbicky ('t al., 1982) The reaction may also lead to aromatization. isomerization ( $c l s$ and trans), disproportionation, hydrogenolysis and rearrangements (Hiroya ef al, 1987 ; House 1972. Isabelle et al., 1977: Rylander, 1973). Finally, this approach to ${ }^{18} \mathrm{~F}$ labeling will not be applicable when either the starting materal or the final products are thermally labile 


\section{Summary}

This procedure demonstrates the feasibility of decarbonylation of substituted $\left[{ }^{18} \mathrm{~F}\right]$ fluorobenzaldehydes to aryl $\left[{ }^{18} \mathrm{~F}\right]$ fluorides, and has been successfully applied to the NCA syntheses of electron rich compounds such as $\left[{ }^{18} \mathrm{~F}\right]$ fluoroanisoles and $\left[{ }^{18} \mathrm{~F}\right]$ fluorophenols.

From a practical point of view, this method is a simple, two step procedure and provides aryl $\left[{ }^{18}\right.$ F]fluorides in moderate yield. The method described here utilizes a nucleophilic aromatic displacement reaction by $\left[{ }^{18} \mathrm{~F}\right]$ fluoride ion in the initial fluorination step and thus should be useful for preparation of a wide variety of $\mathrm{NCA}$ aryl $\left[{ }^{18} \mathrm{~F}\right]$ fluorides which do not have electron withdrawing groups; this sequence is not limited to preparation of fluorophenols (Hawthorne and Wilt, 1960). The synthesis of $3-\left[{ }^{18} \mathrm{~F}\right]$ fluoro-4-methylphenol $\left(\left[{ }^{18} \mathrm{~F}\right] 1\right)$ beginning from 3-fluoro-4-methylphenol (1) also demonstrates the feasibility of preparing aryl $\left[{ }^{18} \mathrm{~F}\right]$ fluorides by use of an essentially removable activating group. As there are a number of methods avalable for the direct introduction of an aldehyde group onto an aromatic ring (March, 1985), a wide range of radiopharmaceuticals might be labeled with $\left[{ }^{18} \mathrm{~F}\right]$ fluoride by this approach.

Acknowledgements - This work was supported by Department of Energy grant DE-FG02-88ER60639. National Institules of Health grant NS 15655 and National Institutes of Health Tranning grant T-32-CA09015 (to P.K.C).

\section{References}

Baıley D M., DeGrazıa C. G, Lape H. E, Frerıng R, Fort D. and Skulan T. (1973) Hydroxyguanıdines. A new class of antihypertensive agents $f$ Med. Chem. 16, 151.

Basa S. C. (1975) Crenulatun, a formyl coumarın from Hesperathusa cremulate (Rutaceae) Aust. J Chem 28, 1159.

Brown J. H , Suckling C. W. and Whalley W B. (1949) Some fluorinated derivatives of toluene $J$. Chem Soc 1, (Suppl.) 95

Carabateas R M., Brundage R. P. Gelotte K. O, Gruett M. D., Lorenz R R., Opalka. C. J. Jr, Singh B , Thuelking W H., Willaams G. L. and Lesher G. Y. (1984) 1-Ethyl1,4-dihydro-4-oxo-7-(pyridinyl)-3-quinoline carboxylic acid. I Synthesis of 3- and 4-(3-aminophenyl)pyridine intermediates $J$ Hetero Chem. 21, 1849.

Chakraborty P. K and Kilbourn M R. (1991) Oxıdation of substituted 4-fluorobenzaldehydes application to the nocarrier-added syntheses of 4-[ $\left.{ }^{18} \mathrm{~F}\right]$ fluoroguaracol and 4$\left[{ }^{18} \mathrm{~F}\right]$ fluorocatechol Appl. Radiat. Isot. 42, 673

Ehrenkaufer R. E , MacGregor R R. and Wolf A P. (1982) Decarbonylation of aroyl fluorides using Wilkınson's catalyst: a reevaluation $J$ Org. Chem. 47, 2489.

Gross H., Rieche A. and Matthey G. (1963) Uber $\alpha$-halogenather XIII Neue verfahren zur darstellung von phenolaldenhyden Chem Ber. 96, 308.

Guddat T.. Herderıng W, Knochel A, Salehı H and Zwernemann O. (1989) N C A. labeling of aromatic compounds with ${ }^{18} \mathrm{~F}^{-} . J$ Labelled Compd Radiopharm. 26, 5 .

Haka M. S., Kılbourn M. R., Watkıns G. L. and Toorongian S. A. (1989) Aryltrimethylammonıum trifluoromethanesulfonates as precursors to aryl ${ }^{18}$ Flfluorides: improved synthesis of $\left[{ }^{18} \mathrm{~F}\right] \mathrm{GBR}-13119 . J$ Labelled Compd. Radiopharm. 27, 823
Hamacher K., Coennen H. H. and Stocklin G. (1986) Efficient stereospecific synthesis of no-carrier-added 2$\left[{ }^{18} \mathrm{~F}\right]$-fluoro-2-deoxy-D-glucose using amınopolyether supported nucleophilic substitution. $J$ Nucl. Med. 27, 235.

Hawthorne J. O. and Wilt M. H. (1960) Decarbonylation of aromatic aldehydes. J. Org. Chem. 25, 2215.

House H. O (1972) Modern Synthetic Reactions, 2nd edn, pp. 34-35. Benjamin, Phılıppınes.

Hwang D.-R.. Dence C. S. and Welch M. J (1991) A two step procedure for labeling unactivated alkylbenzenes with NCA $\left[{ }^{18}\right.$ F]fluoride. J. Labelled Compd Radlopharm. 30, 141 .

Isabelle M. E., Lake D. H. and Nightman R. H. (1977) Tricyclic aromatic hydrocarbon. III. Isomerically pure meta-bis-annelated benzenes: a simple synthesis Can. $J$. Chem. 55, 3268.

Ishi H., Suguıra (nee Hagıwara) T., Akıyama (nee Kondo) Y., Ichukawa Y., Walanabe T. and Murakamı Y. (1990) Fisher indolization and its related compounds. XXIII Fisher indolization of ethyl pyruvate 2-(2,6-dimethoxyphenyl)phenylhydrazone Chem. Pharm Bull 38, 2118

Kilbourn M R. (1990) Fluorine-18 Labeling of Radiophar maceutcals. National Academy Press, Washington, D C.

Kirby G. W., Tan S L. and Uff B. C. (1979) Rearrangement reaction of a Reissert compound chlorohydrin. J. Chem. Soc Perk I 266.

March J. (1985) Advanced Organic Chemistry: Reactions, Mechanisms, and Structure, 3rd edn, pp 487-491. Wiley, New York.

Mulholland $G$ K. Hichwa R D, Kilbourn M. R. and Moskwa J (1989) A relıable pressurized water target for F-18 production at high beam currents $J$. Labelled Compd Radiopharm. 26, 192

Newman M. S. and Zahn H V. (1943) The catalytic dehydrogenation of 2-substituted-5,6,7,8-tetrahydronaphthalene derivatives. $J$ Am Chem. Soc 65, 1097.

Ng J. S , Katzenellenbogen J. A. and Kılbourn M. R. (1981) Aromatic fluorinations suitable for fluorine-18 labeling of estrogens. J Org Chem. 46, 2520.

Rylander P. N (1973) Organic Syntheses with Noble Metal Catalysts, pp 260-271 Academic Press, New York

Satyamurthy N, Bida G. T., Phelps M E. and Barro J. R (1990) $N$-[ ${ }^{8}$ F]Fluoro- $N$-alkylsulfonamides: novel reagents for mild and regioselective radiofluroination Appl Radiat. Isot. 41, 733.

Shirasaka T, Takuma Y. and Imakı N. (1990) Preparation of 2-methoxy-3,4-methylenedioxybenzaldehyde (croweacin aldehyde) from pyrogallol Synth. Comm 20, 1213

Shishido K, Yamashıta A.. Hiroya K., Fukumoto A. and Kametani T (1987) Preferential electrocyclic reaction of $o$-quirionedimethane New roule to dihydronaphthalenes and napthalenes. Chem Lett. 2113.

Shiue C.-Y, Watanabe M., Wolf A. P, Fowler J. S. and Salvador1 P (1984) Application of the nucleophulic substıtution reaction to the synthesis of no-carrier added $\left[{ }^{18} \mathrm{~F}\right]$ fluorobenzene and other ${ }^{18} \mathrm{~F}$-labeled aryl fiuondes $J$ Labelled Compd Radiopharm. 21, 533.

Tadano K., Idogakı Y, Yamada H. and Suamı T. (1987) Ortho ester Claisen rearrangements of three 3-C. (hydroxymethyl)methylene derivatives of hexofuranose: stereoselective introduction of a quaternary center on $\mathrm{C}-3$ of D-ribo-, L-lyxo-, and D-arabino-hexofuranoses. $J$. Org Chem. 52, 1201

Ungnade H. E. and Orwoll E F. (1955) In Organic Synthests, Coll. Vol. III, pp. 130-131 Wiley, New York.

Verbicky J. W. J $r$, Dellacoletta B. A. and Williams L W (1982) Palladium catalyzed decarbonylation of aromatic acyl chlorides. Tetrahed. Lett 371

Wilt J. W. and Abegg V. P. (1968) The palladium-catalyzed decarbonylation of $\beta$-phenylisovaleraldehyde. A notable diminution of the neophyl rearrangement. J. Org. Chem. 33, 923 